\title{
Globicatella sulfidifaciens sp. nov., isolated from purulent infections in domestic animals
}

\author{
1 Laboratorium voor \\ Microbiologie, Faculteit \\ Wetenschappen, \\ Universiteit Gent, \\ Ledeganckstraat 35 , \\ B-9000 Ghent, Belgium \\ 2 Regional Veterinary \\ Investigation Centre, \\ Industrielaan 15, B8820 \\ Torhout, Belgium \\ 3 BCCM ${ }^{\mathrm{TM}} / \mathrm{LMG}$ Bacteria \\ Collection, Laboratorium \\ voor Microbiologie, \\ Faculteit Wetenschappen, \\ Universiteit Gent, Belgium \\ ${ }^{4}$ Faculty of Veterinary \\ Medicine, Ghent \\ University, Salisburylaan \\ 133, B9820 Merelbeke, \\ Belgium
}

\author{
P. Vandamme, ${ }^{1}$ J. Hommez, ${ }^{2}$ C. Snauwaert, ${ }^{3}$ B. Hoste, ${ }^{3}$ I. Cleenwerck, ${ }^{3}$ \\ K. Lefebvre, ${ }^{3}$ M. Vancanneyt, ${ }^{3}$ J. Swings, ${ }^{1,3}$ L. A. Devriese ${ }^{4}$ \\ and F. Haesebrouck ${ }^{4}$
}

Author for correspondence: P. Vandamme. Tel: +32926451 13. Fax: +3292645092. e-mail: Peter.Vandamme@rug.ac.be

\begin{abstract}
DNA-DNA hybridization experiments and comparative 16S rDNA sequence analysis revealed that six isolates from purulent joint and lung infections in calves, from a lung lesion in a sheep, and from a joint infection of a pig represented a novel species belonging to the genus Globicatella. Whole-cell protein electrophoresis and biochemical activity testing revealed that the isolates formed a homogeneous group differing from Globicatella sanguinis, the only species of this genus described to date. These animal isolates were classified as Globicatella sulfidifaciens sp. nov. with LMG $18844^{\top}$ (= CCUG $44365^{\top}$ ), isolated from the lung of a calf, as the type strain. A detailed description of its phenotypic characteristics is presented. Hydrogen sulphide production was found to be a very useful diagnostic feature.
\end{abstract}

Keywords: Globicatella sulfidifaciens sp. nov., cattle, sheep, pig

\section{INTRODUCTION}

Globicatella has been described as a new genus comprising the single species Globicatella sanguis (Collins et al., 1992). This specific epithet was later corrected to 'sanguinis' (Trüper \& de' Clari, 1997). The description was based on the study of strains from human clinical sources including blood, urine and spinal fluid (Collins et al., 1992). Phenotypically, the strains showed some similarity to Streptococcus uberis and the 'bovis' and 'viridans' streptococcal groups, as well as the aerococci. Later studies demonstrated that the genus is phylogenetically most closely related to the recently described Emerococcus genus, to Ignavigranum, Facklamia and Abiotrophia, and to the well-established genus Aerococcus (Collins et al., 1999).

The present paper describes the characterization and classification of relatively slow-growing Gram-variable cocci from purulent infections in animals as members of the genus Globicatella. Despite having a certain resemblance to G. sanguinis, the animal isolates were distinct and appeared to constitute a new species

Abbreviations: $A M C$, 7-amino-4-methyl coumarin; $M U$, methylumbelliferyl.

The GenBank accession number for the 16S rRNA sequence of strain LMG $18844^{\top}$ is AJ297627.
- Globicatella sulfidifaciens sp. nov. - a description of which is given below.

\section{METHODS}

Strains. The present study covers six field isolates which were obtained from severe (usually purulent) lesions in lungs of calves (three strains), from a lung sample from a lamb with acute bronchopneumonia, and from joint fluids of a pig and a calf with polyarthritis (one strain each) (Table 1). All were from necropsies carried out on animals from different farms in Belgium. The infections appeared to be sporadic and of a mixed nature. The bacteria were obtained in large numbers from lesions, but only one strain was found in pure culture in a joint-fluid sample from a calf. Arcanobacterium pyogenes was co-isolated in three out of the six cases. G. sanguinis reference strains and their sources are listed in Table 1.

SDS-PAGE of whole-cell proteins. All strains were grown for $24 \mathrm{~h}$ on brain-heart infusion (BHI) agar (Difco) and incubated at $36-37^{\circ} \mathrm{C}$ in a microaerobic atmosphere containing approximately $5 \% \mathrm{O}_{2}, 10 \% \mathrm{CO}_{2}$ and $85 \% \mathrm{~N}_{2}$. Preparation of cellular protein extracts, PAGE, densitometric analysis, normalization and interpolation of the protein profiles, and numerical analysis were performed as described by Pot et al. (1994) using the GelCompar version 4.2 software package (Applied Maths). The profiles were recorded and stored on a PC. The similarity between all pairs of traces was expressed by the Pearson product-moment correlation coefficient converted, for convenience, to a percentage value. 
Table 1. Globicatella strains investigated

CCUG, Culture Collection, University of Göteborg, Department of Clinical Bacteriology, Göteborg, Sweden; LMG, BCCM/LMG Bacteria Collection, Laboratorium voor Microbiologie Gent, Universiteit Gent, Belgium.

\begin{tabular}{|lll|}
\hline Species and LMG no. & Received as: & Source \\
\hline G. sulfidifaciens & & \\
18837 & GEM 618 & Cattle lung \\
18839 & T2137-2 & Pig joint \\
18842 & GEM 571 & Sheep lung \\
$18844^{\mathrm{T}}$ & GEM 604 & Cattle lung \\
18846 & GEM 565 & Cattle joint \\
18847 & GEM 615 & Cattle lung \\
G. sanguinis & & \\
14367 & CCUG 26778 & Human urine \\
$18987^{\mathrm{T}}$ & CCUG 32999 & Human blood \\
18988 & CCUG 33000 & Human blood \\
18996 & CCUG 33367 & Human blood \\
\hline
\end{tabular}

Preparation of high-molecular-weight DNA. Highmolecular-weight DNA was prepared as described by Pitcher et al. (1989), modified as outlined below. Prior to lysis using guanidium thiocyanate, cells were incubated for $1 \mathrm{~h}$ at $37^{\circ} \mathrm{C}$ in a buffer containing RNase A $\left(200 \mathrm{mg} \mathrm{l}^{-1}\right.$; Sigma), mutanolysin (100 $\mathrm{U} \mathrm{ml}^{-1}$; Sigma) and lysozyme (250 $\mathrm{mg} \mathrm{ml}^{-1}$; Serva). This was followed by treatment with proteinase $\mathrm{K}$ (200 $\mathrm{mg} \mathrm{l}^{-1}$; Merck) for $15 \mathrm{~min}$ at $37^{\circ} \mathrm{C}$.

$16 \mathrm{~S}$ rRNA gene sequence analysis. Part of the rDNA operon, comprising the nearly complete $16 \mathrm{~S}$ DNA, was amplified by using the PCR. The forward primer was 5'-CTGGCTCAGGAC/TGAACGCTG-3', corresponding to positions 1938 of the Escherichia coli $16 \mathrm{~S}$ rRNA numbering system. The reverse primer was 5'-AAGGAGGTGATCCAGCCGCA$3^{\prime}$, complementary to positions $1541-1522$ of the E. coli $16 \mathrm{~S}$ rRNA numbering system. PCR-amplified 16S rDNAs were purified using the QIAquick PCR purification kit (Qiagen). Sequence analysis was performed using an Applied Biosystems 377 DNA sequencer and the protocols of the manufacturer (Perkin-Elmer/Applied Biosystems), using the BigDye Terminator Cycle Sequencing Ready Reaction kit (with AmpliTaq DNA Polymerase, Fs). The sequencing primers were those described by Coenye et al. (1999). Sequence assembly was performed by using the program AUTOASSEMBLER (Applied Biosystems). The consensus sequence of strain LMG $18844^{\mathrm{T}}$ and the sequences of strains belonging to the same phylogenetic group (retrieved from the EMBL database) were aligned and a phylogenetic tree was constructed on the basis of the neigbour-joining method by using the BIONUMERICS software package (Applied Maths). The nearly complete sequences (1375 bases) of the 16S rRNA genes were used for the calculation of similarity levels and for tree construction; unknown bases were excluded from the calculations.

Determination of the DNA base composition. DNA was enzymically degraded into nucleosides as described by Mesbah et al. (1989). The nucleoside mixture obtained was then separated by HPLC, using a Waters Symmetry Shield $\mathrm{C} 8$ column with the thermostat set at $37^{\circ} \mathrm{C}$. The solvent was $0.02 \mathrm{M} \mathrm{NH}_{4} \mathrm{H}_{2} \mathrm{PO}_{4}(\mathrm{pH} 4.0)$ with $1.5 \%$ (v/v) acetonitrile. Non-methylated lambda-phage DNA (Sigma) was used as the calibration reference.
DNA-DNA hybridization. DNA-DNA hybridization experiments were performed with photobiotin-labelled probes in microplate wells as described by Ezaki et al. (1989), using a HTS7000 Bio Assay Reader (Perkin-Elmer) for the fluorescence measurements. The hybridization temperature was $50{ }^{\circ} \mathrm{C}$ in $50 \%(\mathrm{v} / \mathrm{v})$ formamide. Each value given is the mean of at least two hybridization experiments.

Growth characteristics and biochemical activity. Cultural characteristics were studied as described previously (Devriese et al., 1998). API 20 STREP, API 50CH (bioMérieux) and the BBLCRYSTAL Gram-positive ID System (Becton Dickinson) were used to test biochemical activity.

\section{RESULTS AND DISCUSSION}

\section{SDS-PAGE of whole-cell protein}

The whole-cell-protein profiles of the six G. sanguinislike isolates were compared with each other and with those of $G$. sanguinis reference strains that were of human origin. The result of the numerical analysis is shown in Fig. 1. The six G. sanguinis-like isolates had virtually identical whole-cell protein profiles that were

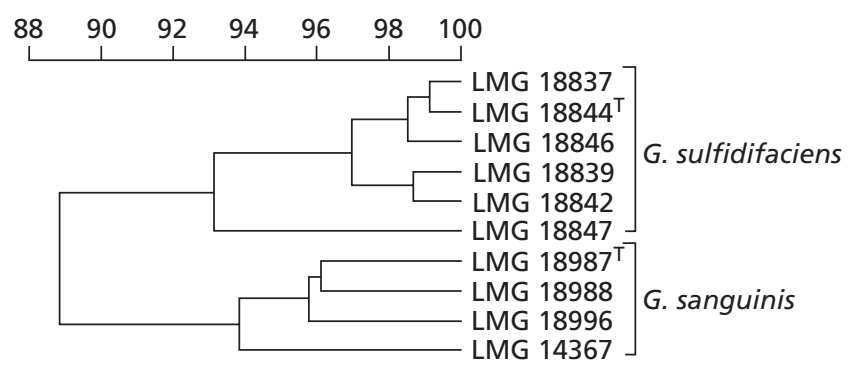

Fig. 1. Dendrogram derived from the unweighted pair group average linkage of correlation coefficients between the wholecell-protein patterns of all Globicatella strains examined. 


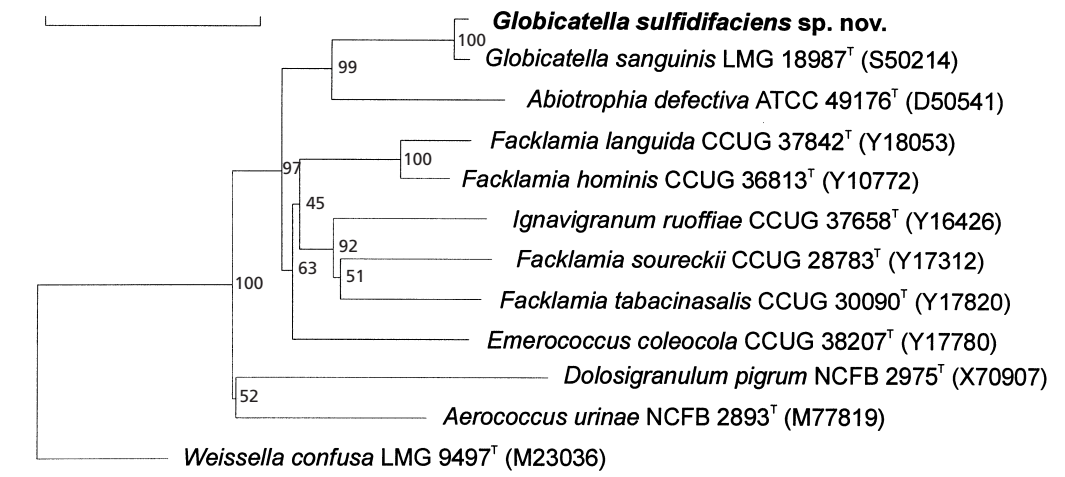

Fig. 2. Neighbour-joining phylogenetic tree of Globicatella sulfidifaciens and related bacteria, based on a comparison of 1375 bases of the $16 \mathrm{~S}$ rRNA sequences. Bar, $5 \%$ sequence dissimilarity. clearly different from those of $G$. sanguinis reference strains. In addition, the latter reference isolates had very similar protein profiles.

\section{S rRNA gene sequence analysis}

The $16 \mathrm{~S}$ rDNA sequence of strain LMG $18844^{\mathrm{T}}$ was examined to determine its phylogenetic position (GenBank no. AJ297627). The level of similarity to the $16 \mathrm{~S}$ rRNA gene of $G$. sanguinis LMG $18987^{\mathrm{T}}$ was $99 \cdot 2 \%$; the level of similarity to the $16 \mathrm{~S}$ rRNA genes of other organisms was below $94 \%$. Fig. 2 shows the result of neighbour-joining cluster analysis of the $16 \mathrm{~S}$ rDNA sequences of strain LMG $18844^{\mathrm{T}}$ and related bacteria.

\section{DNA base composition analysis and DNA-DNA hybridization results}

The close relationship between both taxa was confirmed by DNA base composition analysis and DNADNA hybridization experiments. DNA was prepared from strains LMG $18844^{\mathrm{T}}$ and LMG 18842, and from the G. sanguinis type strain, LMG $18987^{\mathrm{T}}$. The DNA base ratio of strains LMG $18844^{\mathrm{T}}$ and LMG 18842 was $35.8 \mathrm{~mol} \%$; that of LMG $18987^{\mathrm{T}}$ was $35.7 \%$. The DNA-DNA binding value between strains LMG $18844^{\mathrm{T}}$ and $\mathrm{LMG} 18842$ was $90 \%$. The mean value for binding with $G$. sanguinis LMG $18987^{\mathrm{T}}$ was calculated as $68 \%$.

\section{Morphology, growth characteristics and biochemical activity}

The protein electrophoretic differences between these organisms were further supported by salient biochemical differences (Table 2). The cells were predominantly Gram-negative, although Gram-positive cells were always present in the preparations. Most cells tended to occur separately or in pairs, but chains were formed occasionally. Colonies on blood agar were pinpointsized after $1 \mathrm{~d}$ and became grey-white with a diameter of $0.5-1 \mathrm{~mm}$ after $2 \mathrm{~d}$ incubation. They appeared crumbly and dry when removed. Corrosion of the agar surface was seen underneath the colonies. Growth occurred at $25^{\circ} \mathrm{C}$ but was better at 37 and $42{ }^{\circ} \mathrm{C}$.
Supplementation of the incubation atmosphere with $5 \% \mathrm{CO}_{2}$ did not influence growth. The strains showed homogeneous growth after $1 \mathrm{~d}$ in BHI broth, but this sedimented after $2 \mathrm{~d}$. Double-zone haemolysis (an inner, opaque, brownish zone and an outer, semitransparent, greenish ring) was seen on sheep-blood agar.

The strains were unable to grow on bile-aesculin medium but they grew on Edwards agar, and hydrolysed aesculin on this medium. Growth was seen in $6.5 \% \mathrm{NaCl}$ BHI broth after $2 \mathrm{~d}$ incubation. Most characteristically, the strains produced a zone of blackening along the stab inoculation in Kligler's iron agar, indicating hydrogen sulphide production from sulphur-bearing amino acids. These zones were narrow at the tops of the agar columns (in contact with air) and broadened towards the bottom. The slants and the remaining parts of the agar columns turned yellow because of glucose fermentation. Weak amylase production was evident on starch-containing plates. All strains were resistant to neomycins and to the macrolide antibiotics erythromycin, clindamycin and lincomycin. Other biochemical test results are given in Table 2.

\section{Taxonomic position and identification of the G. sanguinis-like isolates}

Together, these data indicate that the human and animal isolates examined are closely related and obviously represent the same genus. Given the clear biochemical differences between both taxa, the differences in whole-cell-protein patterns, and the mean DNA-DNA binding level of $68 \%$, it is appropriate to accommodate the six animal isolates into a novel Globicatella species, for which we propose the name $G$. sulfidifaciens.

The production of hydrogen sulphide, as demonstrated by the deposition of black iron sulphide in Kligler and similar media, is a reaction widely used in the identification of Gram-negative bacteria. The test can be applied to the recognition of Erysipelothrix, but, otherwise, the ability to produce hydrogen in these media is apparently rare in Gram-positive bacteria. The four strains of G. sanguinis available for study 
Table 2. Biochemical characteristics and differentiation between Globicatella sulfidifaciens and Globicatella sanguinis

Differential results are given in body of the table. Globicatella sulfidifaciens strains gave positive reactions in the following tests: $\alpha$-galactosidase, 4 -MU $\beta$-D-glucoside, 4 -MU $\alpha$-D-glucoside, L-pyroglutamic acid AMC, $p$-nitrophenyl $\beta$-D-glucoside, $p$-nitrophenyl $\beta$-D-cellobioside, L-tryptophan AMC (except LMG 18842), proline and leucine- $p$-nitroanilide, $p$-nitrophenyl $\alpha$-D-maltoside, ONPG and $p$-nitrophenyl $\alpha$-D-galactoside, acid production from arbutin, cellobiose, aesculin, D-glucose, glycogen, D-fructose, maltose, D-mannose, melibiose, D-raffinose, saccharose, starch, trehalose and D-xylose; the strains were negative in tests for Voges-Proskauer, hippurate, pyrrolidonyl arylamidase, alkaline phosphatase, arginine dihydrolase, urease, L-valine AMC, L-arginine AMC, 4-MU-phosphate, L-leucine AMC, L-isoleucine AMC, p-nitrophenylphosphate, acid from adonitol, D- and L-arabitol, amygdaline, D-arabinose, dulcitol, erythritol, galactose, $\beta$-gentiobiose, gluconate, methyl $\alpha$-D-glucoside, $N$-acetyl D-glucosamine, glycerol, D- and L-fucose, inositol, lactose, D-lyxose, 2- and 5-ketogluconate, methyl $\alpha$-D-mannoside, melezitose, rhamnose, sorbitol, L-sorbose, D-tagatose, turanose, xylitol, methyl $\beta$-xyloside and $\mathrm{L}$-xylose. Variable reactions were seen with reagents for leucine arylamidase, $\beta$-galactosidase and L-arabinose.

\begin{tabular}{|lcc|}
\hline Characteristic & G. sulfidifaciens & G. sanguinis* \\
\hline $\mathrm{H}_{2}$ S production (Kligler's iron agar) & + & - \\
$\beta$-Galactosidase & - & + \\
$\beta$-Glucuronidase & + & - \\
Hippurate hydrolysis & - & + \\
L-Phenylalanine AMC hydrolysis & + & - \\
4-MU N-acetyl $\beta$-D-glucosaminide & - & - \\
4-MU- $\beta$-D-glucuronide hydrolysis & + & - \\
Acid from: & & + \\
Inulin & + & + \\
Mannitol & - & + \\
Maltotriose & - & + \\
Ribose & - & \\
Methyl $\beta$-glucoside & - & \\
\hline
\end{tabular}

* This table is based on the results of Collins et al. (1999) and our results obtained with the four collection strains used in this study for comparative purposes.

were negative in this test. This indicates that sulphide production is possibly useful in the search for $G$. sulfidifaciens isolates, and in their identification. However, as only a few strains of the two species were investigated, this characteristic should be used cautiously. Other characteristics differentiating the two Globicatella species are listed in Table 2. The differential scheme given by Collins et al. (1999) can be useful for differentiating the Globicatella strains from other recently described phylogenetically related genera. The reactions listed in this table, which may be of use with respect to G. sanguinis, are not, however, entirely applicable to $G$. sulfidifaciens. Notably, the positive hippurate, $\beta$-galactosidase, ribose and mannitol reactions cannot be used as genus-specific characteristics, since they are absent in G. sulfidifaciens. Acid production from melibiose appears to be a characteristic of the genus Globicatella not shared by the related genera as described to date.

G. sulfidifaciens was found most often in clinical samples from ruminants, despite the fact that this category of samples is not the most frequently examined in the laboratory in which the strains were detected. As most of the strains were not isolated in pure culture, the pathological significance of these bacteria is a matter of conjecture. Certainly, their role in lung infections is secondary (much like the situation with $A$. pyogenes). The natural habitat of $G$. sulfidifaciens remains unknown.

\section{Description of Globicatella sulfidifaciens sp. nov.}

Globicatella sulfidifaciens (sul'fi.di.fa'ci.ens. L. n. sulfidum sulphide; L. v. facere produce; N.L. adj. sulfidifaciens sulphide-producing).

Gram-variable cocci showing the characteristics of Gram-positive cocci, occurring singly, in pairs and in short chains. Colonies are dry and corroding. Growth takes 2 d. $\alpha$-Haemolytic. Facultatively anaerobic and catalase-negative. Grows in $6.5 \% \mathrm{NaCl}$ but not on bile-aesculin agar. Glucose is fermented. Other characteristics are given in Table $2 . \mathrm{G}+\mathrm{C}$ content of the DNA is $35-36 \mathrm{~mol} \%$. Isolated from lung and joint lesions in ruminants and a pig. Type strain is LMG $18844^{\mathrm{T}}\left(=\mathrm{CCUG} 44365^{\mathrm{T}}\right)$, which was isolated from a bovine lung in Belgium; its $\mathrm{G}+\mathrm{C}$ content is 
$35.8 \mathrm{~mol} \%$. Its biochemical characteristics are as described above for the species.

\section{REFERENCES}

Coenye, T., Falsen, E., Vancanneyt, M., Hoste, B., Govan, J. R. W., Kersters, K. \& Vandamme, P. (1999). Classification of some Alcaligenes faecalis-like isolates from the environment and human clinical samples as Ralstonia gilardii sp. nov. Int $J$ Syst Bacteriol 49, 405-413.

Collins, M. D., Aguirre, M., Facklam, R. R., Shallcross, J. \& Williams, A. M. (1992). Globicatella sanguinis gen. nov., sp. nov., a new Gram-positive, catalase-negative bacterium from human sources. J Appl Bacteriol 73, 433-437.

Collins, M. D., Rodriguez Jovita, M., Lawson, P. A., Falsen, E. \& Foster, G. (1999). Characterization of a novel Gram-positive, catalase-negative coccus from horses: description of Emerococcus coleocola gen. nov., sp. nov. Int J Syst Bacteriol 49, 1381-1385.

Devriese, L. A., Vandamme, P., Pot, B., Vanrobaeys, M., Kersters, K. \& Haesebrouck, F. (1998). Differentiation between Streptococcus gallolyticus strains of human clinical and veterinary origins and Streptococcus bovis strains from the intestinal tract of ruminants. J Clin Microbiol 36, 3520-3523.

Ezaki, T., Hashimoto, Y. \& Yabuuchi, E. (1989). Fluorometric DNA-DNA hybridization in microdilution wells as an alternative to membrane filter hybridization in which radioisotopes are used to determine genetic relatedness among bacterial strains. Int J Syst Bacteriol 39, 224-229.

Mesbah, M., Premachandran, U. \& Whitman, W. B. (1989). Precise measurement of the guanine plus cytosine content of DNA by high-performance liquid chromatography. Int J Syst Bacteriol 39, 159-167.

Pitcher, D. G., Saunders, N. A. \& Owen, R. J. (1989). Rapid extraction of bacterial genomic DNA with guanidium thiocyanate. Lett Appl Microbiol 8, 109-114.

Pot, B., Vandamme, P. \& Kersters, K. (1994). Analysis of electrophoretic whole-organism protein fingerprints. In Chemical Methods in Prokaryotic Systematics, pp. 493-521. Edited by M. Goodfellow \& A. G. O’Donnell. Chichester: Wiley.

Trüper, H. G. \& de' Clari, L. (1997). Taxonomic note: necessary correction of specific epithets formed as substantives (nouns) ‘in apposition'. Int J Syst Bacteriol 47, 908-909. 